American Journal of Environmental Sciences 6 (6): 495-499, 2010

ISSN 1553-345X

(C) 2010 Science Publications

\title{
Emission and Combustion Characteristics of Si Engine Working Under Gasoline Blended with Ethanol Oxygenated Organic Compounds
}

\author{
${ }^{1}$ Dhanapal Balaji, ${ }^{2}$ Periyasamy Govindarajan and ${ }^{3}$ Jayaraj Venkatesan \\ ${ }^{1}$ Department of Mechanical Engineering, \\ Panimalar institute of Technology, Chennai-602103 \\ ${ }^{2}$ Department of Technology, Sona College, Salem-5 \\ ${ }^{3}$ Department of Mechanical Engineering, \\ Sree Venkateshwara College of Engineering, Chennai-602103
}

\begin{abstract}
Problem statement: The objective of this study is to investigate the effect of using unleaded gasoline and additives blends on Spark Ignition engine (SI engine) combustion and exhaust emission. Approach: A four stroke, single cylinder SI engine was used for conducting this study. Exhaust emissions were analysed for Carbon Monoxide (CO), Hydrocarbon (HC) and Oxides of Nitrogen (NOx) and carbon dioxide $\left(\mathrm{CO}_{2}\right)$ using unleaded gasoline and additives blends with different percentages of fuel at varying engine torque condition and constant engine speed. Results: The result showed that the blending of unleaded gasoline increases the octane number and power output this may leads to increase the brake thermal efficiency. The CO, HC and NOx emissions concentrations in the engine exhaust decreases while the $\mathrm{CO}_{2}$ concentration increases. Conclusion: Using ethanol as a fuel additive to unleaded gasoline causes an improvement in combustion characteristics and significant reduction in exhaust emissions.
\end{abstract}

Key words: Fuel additive, gasoline-additives blend, exhaust emissions, Hydrocarbon (HC)

\section{INTRODUCTION}

It is the dream of engineers and scientists to develop engines and fuels such that very few quantity of harmful emissions are generated and these could be let into the surroundings without a major impact on the environment. Air pollution is predominately emitted through the exhaust of motor vehicles and the combustion of fossil fuels. Government around the world has set forth many regulatory laws to control the emissions. One of the serious problems facing the modern technological society is the drastic increase in environmental pollution by Internal Combustion engines (IC engines). All transport vehicles with SI and CI (compression ignition) engines are equally responsible for the emitting different kinds of pollutants. Some of these are primary kinds having direct hazardous effect such as carbon monoxide, hydrocarbons, nitrogen oxides while others are secondary pollutants such as ozone, which undergo a series of reactions in the atmosphere and become hazardous to health (Goddger, 1978). The emissions exhausted into the surroundings pollute the atmosphere and cause global warming, acid rain, smog, odours and respiratory and other health hazards. The urgent need for alternative fuel is essential to replace the supplement conventional fuels. A pollutant is a component which changes the balance of environment and nature under normal condition. Carbon dioxide is not considered as pollutant as nature recycles it and produces oxygen but in a confined area if $\mathrm{CO}_{2}$ exceeds $5000 \mathrm{ppm}$ then it becomes a potential health hazard (Bata and Roan, 1989). The root cause for these emissions is non-stoichiometric combustion, dissociation of nitrogen and impurities in the fuel and air. The transportation which uses IC engines is the major sector for the economic growth. The major exhaust emissions $\mathrm{HC}, \mathrm{CO}, \mathrm{NOx}, \mathrm{SO}_{2}$, solid particles are and performance is increased by adding the suitable additives to the fuel reduced with the present technology. Additives are integral part of today's fuel. Together with carefully formulated base fuel composition they contribute to efficiency and long life. They are chemicals, which are added in small quantities either to enhance fuel performance, or to correct a deficiency as desired by the current legislation. They can have surprisingly large effects even when added in little amount. Additives are blended into fuel by 
Am. J. Environ. Sci., 6 (6): 495-499, 2010

refineries or end users. However use of metallic additives was subsequently discontinued mainly because of concern about the toxicity of the barium compounds in the exhaust emission. But the interest is revised recently to verify the possible use of additives to reduce emission level. Alcohol has been used as a fuel for Auto-engines since 19th century; it is not widely used because of its high price. Alcohol is one of the fuel additive (Methanol, Ethanol) has some advantage over gasoline such as better antiknock characteristics and the reduction of $\mathrm{CO}$ and $\mathrm{HC}$ emissions. Houghton-Alico (1982) has made a study on alcohol production and potential. Several additives (oxygenated organic compounds) such as methanol, ethanol, tertiary butyl alcohol and methyl tertiary butyl ether are used as fuel additives. Although having these advantages, due to limitations in technology, economic and regional considerations alcohol fuel still cannot be used extensively. Since ethanol can be fermented and distilled from biomasses, it can be considered as renewable energy under the environmental consideration, using ethanol blended with gasoline is better than methanol because of its renewability and less toxicity.

Many researchers have worked on the emission control and performance enhancement of SI engines. Winnington and Siddique (1983); Hamdan and Jurban (1986) and El-Kassaby (1993) have studied the effect of using ethanol-gasoline blends. They used maximum of $15 \%$ of ethanol in ATd 34 engine. Palmer (1986) has conducted a test on gasoline engine containing oxygenates. The effect of oxygenate in gasoline on exhaust emission and performance in a single cylinder, four stroke SI engine was studied. Ethanol can be produced form Azeotropic Solution by Pressure Swing Adsorption was studied by Pruksathorn and Vitidsant (2009). The effect of compressed natural Gas on performance and Emission in a Internal Combustion engine was studied by Semin et al. (2009a; 2009b) and (Kaleemuddin and Rao, 2009).

Based on the economic and environmental considerations, an attempt has been made in this study to study the effects of ethanol contents in the ethanolgasoline blended fuel on the engine performance and pollutant emission of a commercial SI engine. In the present study, to reduce the emissions and to improve the performance of petrol engine, the modification technique is used. Two fuel additives were mixed for this purpose. Various proportions of these fuel additives were mixed with the gasoline. The engine performance analysis and emission levels were measured, running the engine at varying load and constant speed. Encouraging results were obtained and the work carried out is presented. The objective of the present study is to investigate the effect of varying engine torque on the engine performance and exhaust emission working with different ethanol fuel blends.

\section{MATERIALS AND METHODS}

The engine is a 100 cc 4 stroke, single cylinder SI engine loaded by an eddy current dynamometer. Table 1 lists some of the important specification of the engine under test. The schematic layout of the experimental set up is shown in Fig. 1. The engine was coupled to a eddy current dynamometer which is quipped with an instrument cabinet fitted with a torque gauge, electric tachometer and switches for the load remote control. Fuel consumption was measured by using a calibrated burette and a stopwatch with an accuracy of $0.2 \mathrm{~s}$. The concentration of exhaust emission (CO, HC, NOx) and air fuel ratio were measured using a "Sun glass Analyser" MGA 1200. The analyser has a nondispersive infrared molecule for CO, HC and NOx.

The engine was started and allowed to warm up for a period of 20-30 min. The air fuel ratio was adjusted to yield maximum power on unleaded gasoline. Engine test were performed at constant engine speed at $3 / 4^{\text {th }}$ throttle opening position by varying engine torque. The speed can be maintained constant by speed sensor. Before running the engine to a new fuel blend, it was allowed to run for sufficient time to consume the remaining fuel from the previous experiment. For each experiment, three runs were performed to obtain an average value of the experimental data. The variables that were continuously measured include engine speed (constant), torque, time required to consume $100 \mathrm{cc}$ of fuel blend, CO, HC, NOx emission and exhaust gas temperature. The parameters such as fuel consumption rate, volumetric efficiency, brake power, brake thermal efficiency were estimated by standard equations. Table 1 shows the engine specification.

\begin{tabular}{ll} 
Table 1: Engine specifications & \\
\hline Engine make and model & Bajaj engine \\
Engine type & $\begin{array}{l}\text { Four stroke, Single } \\
\text { cylinder air cooled engine }\end{array}$ \\
Bore & $70 \mathrm{~mm}$ \\
Stroke & $90 \mathrm{~mm}$ \\
Cubic capacity & $100 \mathrm{cc}$ \\
Compression ratio & $7.4: 1$ \\
Rated power & $5.2 \mathrm{~kW}$ \\
Rated speed & $6500 \mathrm{rpm}$ \\
Fuel & Petrol \\
\hline
\end{tabular}


Am. J. Environ. Sci., 6 (6): 495-499, 2010

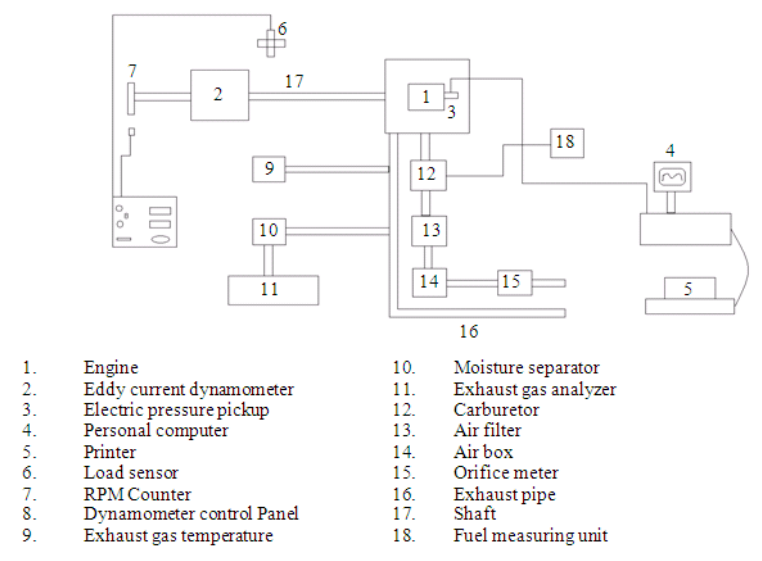

Fig. 1: Experimental setup

\section{RESULTS AND DISCUSSION}

The effect of ethanol addition to unleaded gasoline on SI engine performance and exhaust emissions at 3/4th throttle opening at various engine torque were investigated.

\section{Ethanol gasoline blends: \\ Emission analysis:}

Carbon monoxide: The effect of the Ethanol percentage in the fuel blend on $\mathrm{CO}$ emission is shown in Fig. 2. Figure 2 shows that the CO emission decreases as compared with pure gasoline fuel for various blends. Due to better combustion these emissions are decreased. At the maximum load for all the fuels the specific emission of carbon monoxide is around $1.5-2 \%$ volume. At part load, the specific emission of carbon monoxide is around $3.9 \%$ volume for $30 \%$ of ethanol and $4.8 \%$ volume for pure gasoline. This effect is attributed because the stoichiometric air-fuel ratio of the ethanol blends decreases and increase of actual air-fuel ratio of the ethanol blends as a result of the oxygen content in the ethanol.

Oxides of nitrogen: The effect of the Ethanol percentage in the fuel blend on NOx emission is shown in Fig. 3. Figure 3 shows that the NOx emission decreases as compared with pure gasoline fuel for various ethanol blends. This is because of peak pressure of ethanol blends decreases at the same time the peak cycle temperature of the ethanol fuel blends also decreases. So, NOx emission decreases for all ethanol fuel blends.



Fig. 2: Engine torque-CO emission chart

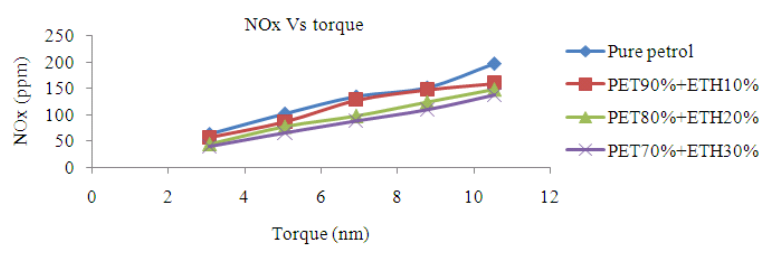

Fig. 3: Engine torque-NOx emission chart

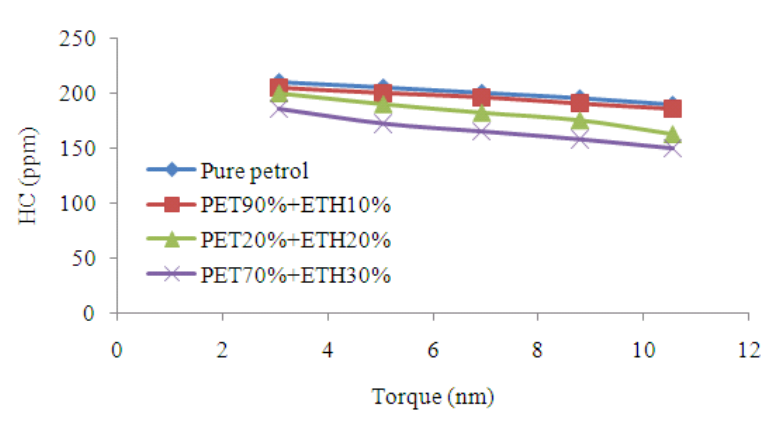

Fig. 4: Engine torque-HC emission chart

Hydrocarbon: The effect of the Ethanol percentage in the fuel blend on HC emission is shown in Fig. 4. Figure 4 shows that the HC emission decreases as compared with pure gasoline fuel for various blends. Due to better combustion these emissions are decreased. This effect is attributed because the stoichiometric air-fuel ratio of the ethanol blends decreases and increase of actual air-fuel ratio of the ethanol blends as a result of the oxygen content in the ethanol.

Carbon dioxide: The effect of the Ethanol percentage in the fuel blend on HC emission is shown in Fig. 5. Figure 5 shows that the carbon dioxide increases as compared with pure gasoline fuel for various ethanol blends. The $\mathrm{CO}_{2}$ concentrations have an opposite behaviour when compared to $\mathrm{CO}$ concentrations. This is due to improving combustion process as a result of the oxygen content in the ethanol fuel. 
Am. J. Environ. Sci., 6 (6): 495-499, 2010

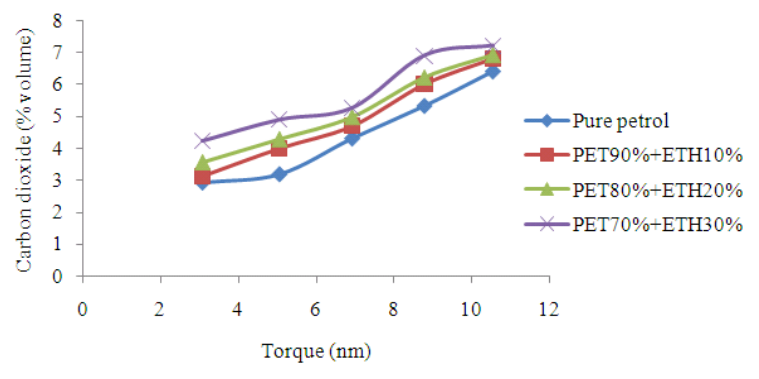

Fig. 5: Carbon dioxide Vs torque

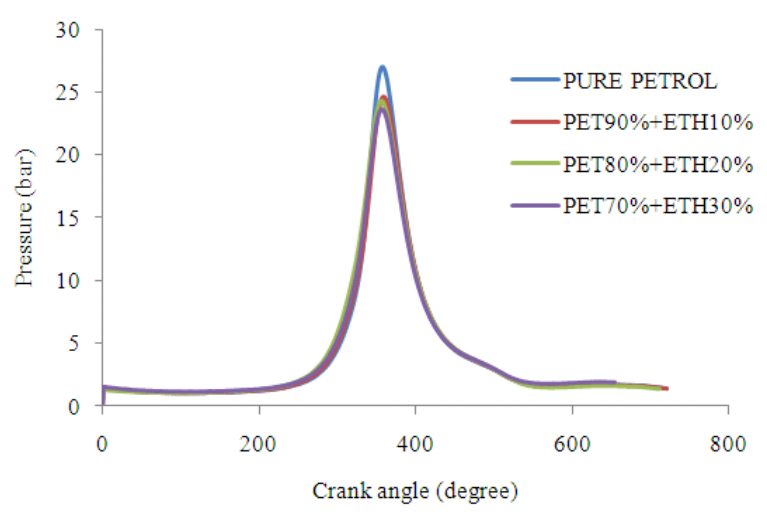

Fig. 6: Pressure Vs crank angle

\section{Combustion analysis:}

Pressure- Crank angle chart: Figure 6 shows the effect of adding ethanol to gasoline fuel on the pressure- crank angle diagram. It can be seen from this figure that the pure gasoline has maximum pressure than blended fuel. The maximum pressure for pure gasoline is 27 bar. However the same figure shows that increasing the ethanol percentage $(10 \%, 20 \%$ and $30 \%)$ results in a decrease of the maximum pressure to a value of 24.5, 24 and 23 bar respectively. This may be explained as follows: the addition of ethanol to gasoline has two effects on the fuel properties; the first is an increase of the Octane number since the latent heat of evaporation of ethanol is much greater than that of gasoline and accordingly, ethanol addition helps to delay the chain reactions of the end gas; the second is a decrease in heating value or calorific value.

Heat release rate- crank angle chart: Figure 7 shows the effect of adding ethanol to gasoline fuel on the heat release rate diagram. It can be seen from this figure the maximum heat release rate occurs for pure gasoline 20 degrees aTDC. By adding ethanol with gasoline the flame speed may be increased to some extent thereby the maximum heat release rate occurs 19, 18 and 17 degrees aTDC for 10, 20 and 30\% of ethanol blends respectively.

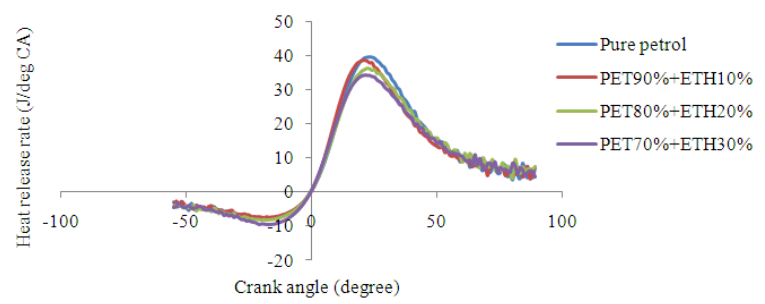

Fig. 7: Heat release rate Vs crank angle

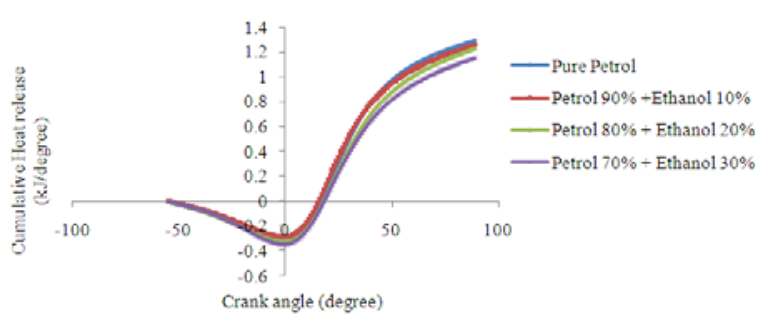

Fig. 8: Heat release rate Vs crank angle

The addition of ethanol with pure gasoline decreases the overall heating value therefore the heat release rate as reduced compared to the pure gasoline. The negative heat release rate for the ethanol blends has more compare to the pure gasoline. This is due to increase of latent heat of vaporization of the blends.

Cumulative heat release-crank angle chart: Figure 8 shows the effect of ethanol adding to gasoline fuel on cumulative heat release diagram. The cumulative heat release is mainly depends on the heat input and combustion efficiency. For this particular application the combustion efficiency is taken as constant but the heat input to the engine is varied by adding ethanol with various percentages to the pure gasoline. So, the overall calorific value of the mixture is decreases with the percentage of increase of ethanol. So, the cumulative heat release for the ethanol added fuels may reduce because of the calorific value of the mixture.

\section{CONCLUSION}

- Using ethanol as a fuel additive to unleaded gasoline causes an improvement in combustion characteristics and significant reduction in exhaust emissions

- Using ethanol-unleaded gasoline blend leads to a significant reduction in exhaust emissions by about $46.5 \%, 24.3$ and $18.2 \%$ of the mean average values of CO, HC and NOx emission respectively for all engine torque. On the other hand blending of all ethanol fuels the $\mathrm{CO}_{2}$ concentration increases 
Am. J. Environ. Sci., 6 (6): 495-499, 2010

- The addition of ethanol to unleaded gasoline the maximum pressure will be reduced for ethanol blends to about $4,5.5$ and $6.8 \%$ respectively

- From the heat release rate cure the negative heat release rate of ethanol blends increased. To reduce the negative heat release rate by heating the inlet air temperature this may improve the performance characteristics

- $\quad$ By adding the ethanol with pure gasoline the flame speed will increase, so that the spark timing of ethanol blends has to be optimized. This may improve the performance

- The peak pressure occurrence has advance for ethanol blends than pure gasoline, so spark timing has to be retarded. This may influence the performance characteristics

- By adding the ethanol with pure gasoline with various percentages the octane number of ethanol blends are increased. This leads to increase the compression ratio and power output. So, brake thermal efficiency of ethanol blends increased

\section{ACKNOWLEDGEMENT}

The researchers would like to thank the technical staff of the ICE laboratory at the Mechanical Engineering Department of Sona College of Technology.

\section{REFERENCES}

Bata, R.V. and V.P. Roan, 1989. Effects of ethanol and methanol in alcohol-gasoline blends on exhaust emissions. J. Eng., Gas Turbine Power, 111: 432-438. DOI: 10.1115/1.3240272

EL-Kassaby, M.M., 1993. Effect of using differential ethanol-gasoline blends at different compression ratio on SI engine. Alexandria Eng., 32: 135-142.

Goddger, E.M., 1978. Comparative energies of lternative fuels. Applied Energy, 4: 39-50. DOI: 10.1016/0306-2619(78)90018-1
Houghton-Alico, D., 1982. Alcohol Fuels: policies, Production and Potential. 1st Edn., Westview Press, Colorado, pp: 268. ISBN: 0865312451

Hamdan, M.A. and B.A. Jubran, 1986. The effect of ethanol performance of diesel and petrol engines. Dirasat, 13: 229-244.

Kaleemuddin, S. and G.A.P. Rao, 2009. Development of dual fuel single cylinder natural gas engine an analysis and experimental investigation for performance and emission. Am. J. Applied Sci., 6: 929-936. DOI: 10.3844/ajessp.2009.929.936

Palmer, F.H., 1986. Vehicle performance of gasoline containing oxygenates. Proceeding of the paper C319/86, International Conference on Petroleum Based Fuels and Automotive Applications, (ICPBFA'86), I. Mech. E. Conference, London, pp: 36-46.

Pruksathorn, P. and T. Vitidsant, 2009. Production of pure ethanol from azeotropic solution by pressure swing adsorption. Am. J. Eng. Applied Sci., 2: 1-7. DOI:10.3844/ajeassp.2009.1.7

Semin, R.A. Baskar and A.R. Ismail, 2009a. Green engines development using compressed natural gas as an alternative fuel: A review. Am. J. Environ. Sci., $\quad$ 5: 371-381. 10.3844/ajessp.2009.371.381

Semin, A.R. Ismail and R.A. Baskar, 2009b. Combustion temperature effect of diesel engine convert to compressed natural gas engine. Am. J. Eng. Applied Sci., 2: 212-216. DOI: 10.3844/ajessp.2009.212.216

Winnington, T.L. and K.M. Siddiqui, 1983. Engine performance on gasohol-the Kenyan experience. Automotive Eng., 8: 12-23. 